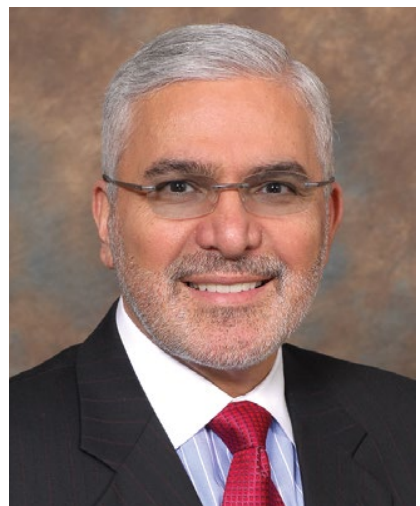

Henry A. Nasrallah, MD Editor-in-Chief doi: 10.12788/cp.0062

Novel pharmacotherapies are needed to address the gaps in the clinical care of our patients

\title{
Unmet needs in the pharmacotherapy of psychiatric brain syndromes
}

Let's face it: The greatest unmet need in psychiatry is discovering a treatment for the infamous syndrome of toxic political extremism. Its ugly symptoms include blind hatred, visceral malice, bigotry, vandalism, hypocrisy, racism, hubris, intransigence, narcissism, demagoguery, mutual contempt, and intense schadenfreude.

This corrosive affliction has engulfed and polluted our society, and compromised our well-being and quality of life. Treating this malignant syndrome is beyond the reach of psychopharmacology!

Thus, we psychiatrists should focus on the mood, psychotic, anxiety, and addiction syndromes that we encounter daily in our hospitals, clinics, and private offices. They affect tens of millions of patients. We currently have many psychotropic medications for these conditions. When combined with psychotherapy, the resulting synergy can be magical and immensely gratifying. However, some of those agents have limited efficacy due to the extensive heterogeneity of syndromes such as schizophrenia or depression, which are often confounded with comorbidities. A perfect balance between efficacy, tolerability, and safety are often hard to come by in pharmacotherapy.

The most glaring psychopharmacologic unmet need is that $80 \%$ of DSM disorders still do not have a single FDA-approved (evidence-based) medication. ${ }^{1}$ It will take decades, hundreds of billions of dollars, and the motivation of the often-maligned pharmaceutical industry (indispensable, because they are the only entity with the large R\&D infrastructure to develop medications for psychiatry). Both academic and clinical psychiatrists must advise pharmaceutical companies about the unmet needs in our field and urge them to develop novel pharmacotherapies to address the gaps in the clinical care of psychiatric patients.

\section{An inventory of unmet needs}

With that in mind, here is a list of unmet needs I have been thinking about lately, and hoping that they will be resolved to help our patients achieve better clinical and functional outcomes.

Rapid-onset antipsychotics. The discovery that ketamine can rapidly convert refractory patients who are chronically depressed or suicidal to normal mood within a few hours shattered the dogma that weeks and months are needed for severe depression to improve, let alone achieve full remission. There is a similar dogma about psychosis requiring 
continued from page 14

a protracted duration of antipsychotic treatment to attain significant impact. A rapid-acting antipsychotic agent would represent a major advance in psychiatry and its pharmaco-economic benefits would be substantial, given the high cost of inpatient hospitalization. Just as neurobiologic research guided the discovery of ketamine as a dramatic paradigm shift in treating depression, targeted research, especially focusing on glutamate pathways, may help identify a rapid-onset agent, whether oral, intranasal, IV, or even (why not) intrathecal. Research is known to enhance serendipity, which has been kind to psychiatry and has led to the discovery of several pharmacologic therapies in psychiatry, such as chlorpromazine, monoamine oxidase inhibitor antidepressants, and lithium.

Long-acting antidepressants and anxiolytics. This can be regarded as lowhanging fruit. Several technologies have been developed for long-acting formulations, yet they have been exploited mainly for antipsychotic medications. Some of these technologies can be employed to convert commonly used antidepressants (such as selective serotonin reuptake inhibitors) into long-acting antidepressants that can also reduce anxiety. Nonadherence among patients with depression is quite common, and relapses may lead to suicide attempts. The use of injectable, long-acting antidepressants can also reduce the incidence of overdoses because the patient will not have possession of potentially fatal pills.

Long-acting mood stabilizers. The rationale for long-acting mood stabilizers is the same as for long-acting antidepressants. Patients with bipolar disorder are known to stop taking their medications because they miss their "highs." Some long-acting antipsychotics are approved for bipolar disorder, but these are often associated with adverse effects, such as metabolic dysregulation, extrapyramidal symptoms, and tardive dyskinesia. Mood stabilizers are essential for the bipolar spectrum.

\section{A "real" treatment for alcohol use dis-} orders that eliminates craving for alcohol. Alcoholism is associated with more than 100 medical complications and is one of the leading causes of disability in the world. It is frustrating that very few drug companies have focused on this widely prevalent brain disorder, which is also a common comorbid condition in many psychiatric syndromes.

Treatment-resistance pharmacotherapy solutions. All psychiatric syndromes are heterogeneous and contain $\geq 1$ subgroups (biotypes) that fail to respond to what is considered the "standard" psychopharmacologic treatment (such as antipsychotics, antidepressants, mood stabilizers, or anti-obsessive medications). Technically, those so-called treatment-resistant subtypes need medications with a different mechanism of action. For example, clozapine for treatment-resistant schizophrenia and ketamine for treatment-resistant depression provide proof that treatment resistance is treatable but by a mechanism of action that is completely different from that of standard therapies, such as N-methyl-D-aspartate (NMDA) receptor modulation. And there is a need for more than one pharmacotherapy for treatment resistance because some patients do not respond to either clozapine or ketamine.

Negative symptoms of schizophrenia cause significant functional disability and are well known to be a major unmet need. Some promising data are emerging on agents such as pimavanserin, cariprazine, and roluperidone, which is encouraging, but nothing is approved yet.

Cognitive deficits of schizophrenia, both neurocognition and social cognition, are another major unmet need that
Editorial Staff

EDITOR Jeff Bauer

SENIOR EDITOR Sathya Achia Abraham ASSISTANT EDITOR Jason Orszt

WEB ASSISTANTS

Tyler Mundhenk, Kathryn Wighton

Art \& Production Staff

CREATIVE DIRECTOR Louise Koenig

ART DIRECTOR Pat Fopma

DIRECTOR, JOURNAL MANUFACTURING Michael Wendt

PRODUCTION MANAGER Donna Pituras

Publishing Staff

PUBLISHER Sharon Finch

DIRECTOR EBUSINESS DEVELOPMENT

Alison Paton

SENIOR DIRECTOR OF SALES

Tim LaPella

Editor-in-Chief Emeritus

James Randolph Hillard, MD

Frontline Medical Communications

VP, SALES Mike Guire

VP, DIGITAL CONTENT \& STRATEGY Amy Pfeiffer

PRESIDENT, CUSTOM SOLUTIONS JoAnn Wahl

CIRCULATION DIRECTOR Jared Sonners DIRECTOR, CUSTOM PROGRAMS

Patrick Finnegan

In affiliation with Global Academy for Medical Education, LLC

PRESIDENT David J. Small, MBA

\section{FRONTLINE MDedge}

7 Century Drive, Suite 302

Parsippany, NJ 07054

Tel: (973) 206-3434

Fax: (973) 206-9378

www.frontlinemedcom.com

Subscription Inquiries:

subscriptions@mdedge.com

Published through an

educational partnership with

l(C CINCINNATI

Current Psychiatry 
It will take a massive collaboration among multiple stakeholders to begin addressing the unmet needs of many psychiatric disorders impair function in many patients. Many attempts to develop a pharmacologic treatment for these serious cognitive impairments have been made, but several candidates that initially appeared promising have bitten the dust. A focus on modulating the glutamate NMDA receptor may eventually lead to a breakthrough, and that may also help patients with bipolar disorder and major depressive disorder, both of whom also have cognitive deficits in several domains, albeit less severe than those experienced by patients with schizophrenia.

Personality disorders, especially borderline personality disorder, are very challenging to treat pharmacologically despite their prevalence and serious disruption to people's lives. Hardly any FDA clinical trials have been conducted on any personality disorder. It is an unmet need that all psychiatrists would love to see addressed. But the mythical notion that personality disorders are untreatable may be an impediment in the pursuit of novel pharmacotherapy for borderline, narcissistic, antisocial, or schizotypal personality disorders, and other disorders. Heart attacks and religious conversion often change the baseline personality dramatically.

Childhood disorders. Apart from attention-deficit/hyperactivity disorder (ADHD), very few childhood psychiatric disorders have an FDA-approved medication. Why do drug companies avoid conducting controlled clinical trials in children age $<10$ who have autism, spectrum disorders, conduct disorder, oppositional defiant disorder, and other disorders? Effective pharmacotherapy for these children can be regarded as a desirable early intervention that may short-circuit their progression to serious adult psychopathology.

Parsimonious psychopharmacology for the treatment of trans-diagnostic psychiatric disorders. Recent research strongly suggests there is a strong overlap among psychiatric conditions, genetically, clinically, and biologically., ${ }^{2,3}$ For example, bipolar disorder is frequently accompanied by anxiety or substance use, patients with schizophrenia often experience anxiety, depression, or substance use, and ADHD has been found to share genes with autism. ${ }^{4,5}$

Eating disorders. There are no truly efficacious pharmacologic treatments for anorexia or bulimia nervosa. Research in this area is thin, and needs to be beefed up.

Sexual disorders. A huge unmet need exists for the pharmacotherapy of many sexual disorders that can have serious legal consequences (paraphilias) or quality-of-life repercussions (low sexual desire and orgasm disorders).

\section{A coordinated effort}

It will take a massive collaboration among multiple stakeholders to launch the herculean process of addressing the unmet needs of all the above psychiatric disorders. This includes:

- the pharmaceutical industry (to provide the massive financial investment and R\&D expertise)

- the federal government (to provide incentives)

- the FDA (to allow novel clinical trial designs)

- academic psychiatrists (to conduct research to discover the pathophysiology of psychiatric diseases)

- clinical psychiatrists (to provide consultations and advise about the clinical gaps in current psychopharmacological treatments)

- psychiatric patients (who are needed to volunteer for large-scale clinical trials).

This will be a veritable "psychiatric Manhattan Project" to advance the treatment of numerous psychiatric illnesses. The greatest benefit 


\section{Issue Frequency
Monthy}

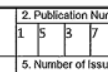

$$
\text { 5. Nur }
$$

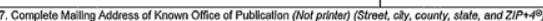
Frontine Modical Communications Inc., 7 Century Orive, Sulte 302, Parsippany, Morris County, NJ 07054-4600

8. Complete Maling Address of Headquarters of General Business Office of Publister (Not printer) Contact Person
Jared Sonners Telephone (inchude area cocose)

7 Century Divive, Sulte 302 , Parsippany, NJ $07054-4609$

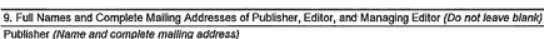

Sharon Finch, 7 Century Drive, Suite 302, Parsippany, NJ 070544609 Edror (Name and completele mating addreass)

Jeff Bauer, 7 Century Drive, Suite 302, Parsippany, NJ 07054-4609

Managing Edilor (Name and completele malling addrosss)

Sathya Achia Abraham, 7 Century Orive, Sulte 302, Parsippany, NJ 07054-4609

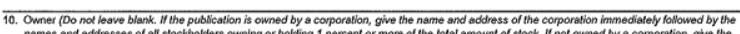

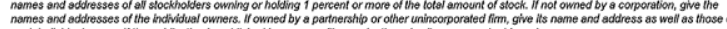

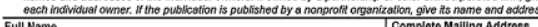

\begin{tabular}{l|l}
\hline Frontline Medical Communications Inc. & 7 Century Drive, Suite 302, Parsippany, NN 07054-4609 \\
\hline
\end{tabular}

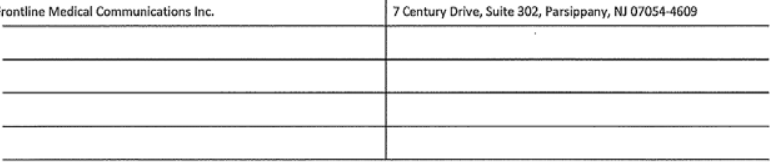

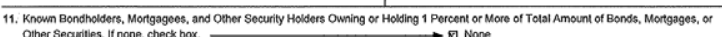

Other Securilies. If none, check box. $\longrightarrow$ id None

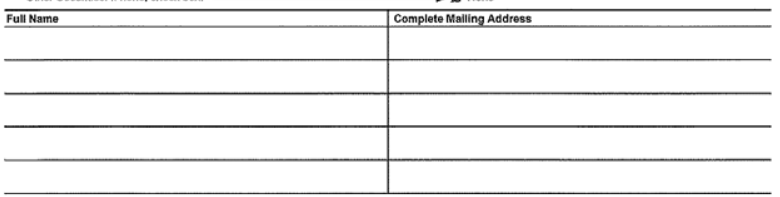

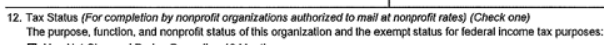

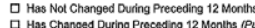

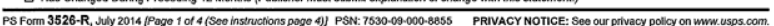

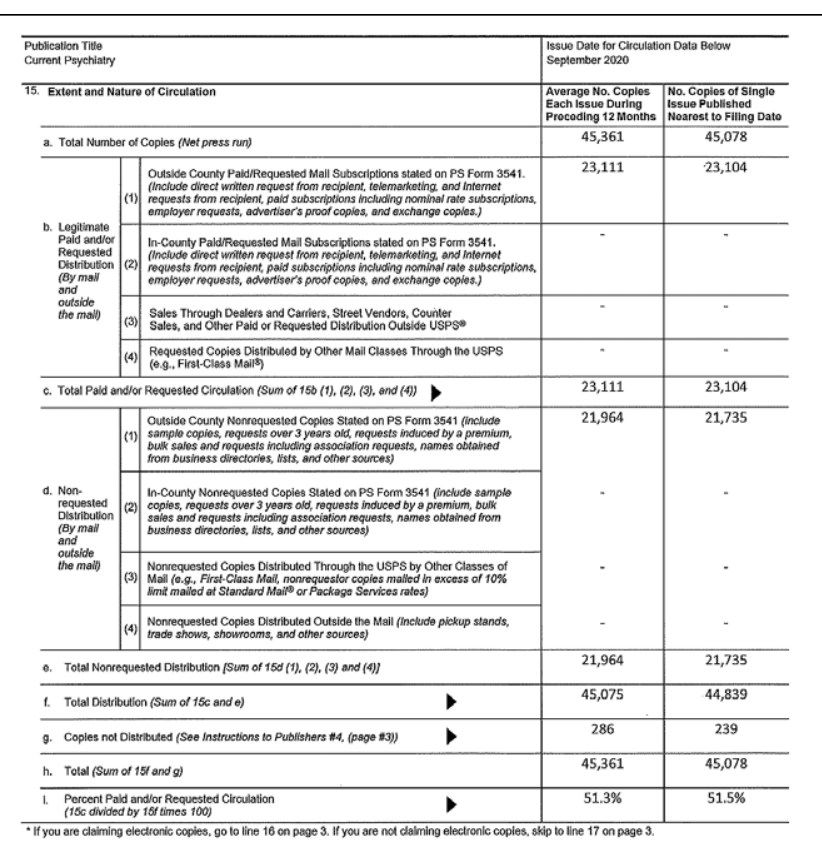

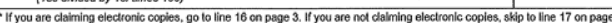

$\rightarrow$ UNITED STATES Statement of Ownership, Management, and Circulation UNITED STATES POSTAL SERVIC

\begin{tabular}{|c|c|c|c|}
\hline \multirow{2}{*}{ POSTAL SERVICE } & \multicolumn{3}{|c|}{ (Requester Publications Only) } \\
\hline & & 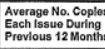 & $\begin{array}{l}\begin{array}{l}\text { No. Coplos of Singlo } \\
\text { issue Published } \\
\text { Nearost to Filling Date }\end{array} \\
\end{array}$ \\
\hline a. Requested and Paid Electronic Coples & D & - & $\cdot$ \\
\hline 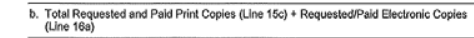 & 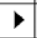 & $\cdot$ & $\cdot$ \\
\hline 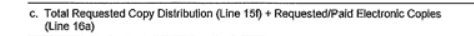 & 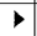 & - & $\cdot$ \\
\hline $\begin{array}{l}\text { d. Percent Paida andior Requested Circulation (Both Print \& Electronic Copies) } \\
\text { (16bodividedby } 16 \mathrm{cc} \text { (100) }\end{array}$ & $\nabla$ & - & - \\
\hline \multicolumn{4}{|c|}{ I certily that 50\% of all my distrtibuted coples (electronic and print) are legitimate requests or paid copies. } \\
\hline \multicolumn{4}{|c|}{$\begin{array}{l}\text { 17. Publication of Statement of Ommership for a Requester Publication is required and will be pinited in the November } 2020 \\
\text { issue of this pubicantion. }\end{array}$} \\
\hline \multicolumn{2}{|l|}{ 18. Signature and Tille of Edillox, Publisher, Business Manager, of Owner } & \multicolumn{2}{|c|}{ Date } \\
\hline \multicolumn{2}{|l|}{ Elizabeth-Ann Buehler $\quad$ SVP, Operations } & \multicolumn{2}{|c|}{$09 / 28 / 20$} \\
\hline
\end{tabular}

\section{Editor}

From the Editor

continued from page 20

of discovering cures for disabling mental disorders is the evaporation of the virulent stigma that continues to plague our patients.

As for the political extremism that has corroded our society, it may be beyond pharmacologic redemption. An antidote to the "kool aid" has not yet been invented...

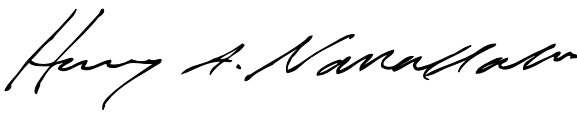

\section{Henry A. Nasrallah, MD}

Editor-in-Chief

\section{References}

1. Devulapalli KK, Nasrallah HA. An analysis of the high psychotropic off-label use in psychiatric disorders: the majority of psychiatric diagnoses have no approved drug. Asian J Psychiatr. 2009;2(1):29-36.

2. Nasrallah HA. Is there only 1 neurobiologic disorder, with different clinical expressions? Current Psychiatry. 2015; 14(7):10-12.

3. Nasrallah HA. Pleiotropy of psychiatric disorders will reinvent DSM. Current Psychiatry. 2013;12(4):6-7.

4. Caspi A, Moffitt TE. All for one and one for all: mental disorders in one dimension. Am J Psychiatry. 2018;175(9): 831-844.

5. Marshall M. Roots of mental illness. Nature. 2020;581:19-21 